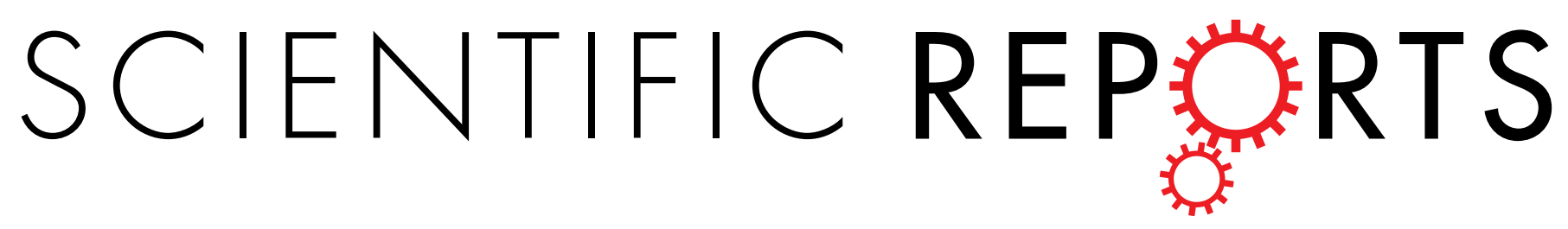

\title{
Erratum: From link-prediction in brain connectomes and protein interactomes to the local- community-paradigm in complex networks
}

Carlo Vittorio Cannistraci, Gregorio Alanis-Lobato \& Timothy Ravasi

Scientific Reports 3:1613; doi: 10.1038/srep01613; published online 08 April 2013; updated 21 July 2015 This Article contains typographical errors in Table 1.

The formulation for Jaccard (JC)

$$
J C(x, y)=\frac{|\Gamma(x) \cap \Gamma(y)|}{|\Gamma(x) \cap \Gamma(y)|}=\frac{C N(x, y)}{|\Gamma(x) \cap \Gamma(y)|}
$$

should read:

$$
J C(x, y)=\frac{|\Gamma(x) \cap \Gamma(y)|}{|\Gamma(x) \cup \Gamma(y)|}=\frac{C N(x, y)}{|\Gamma(x) \cup \Gamma(y)|}
$$

The formulation for CJC

$$
\operatorname{CJC}(x, y)=\frac{C A R(x, y)}{|\Gamma(x) \cap \Gamma(y)|}
$$

should read:

$$
\operatorname{CJC}(x, y)=\frac{\operatorname{CAR}(x, y)}{|\Gamma(x) \cup \Gamma(y)|}
$$

